Avrupa Bilim ve Teknoloji Dergisi

Özel Sayı 32, S. 754-760, Aralık 2021

(C) Telif hakkı EJOSAT'a aittir

Araștırma Makalesi

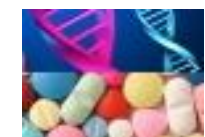

www.ejosat.com ISSN:2148-2683
European Journal of Science and Technology Special Issue 32, pp. 754-760, December 2021

Copyright (C) 2021 EJOSAT

$\underline{\text { Research Article }}$

\title{
Paralel Kinematik Yapıya Dayalı 5-DOF FDM Yazıcı Tasarımı ve İmalatı
}

\author{
Ahmet Dumlu $^{1 *}$, Mehran Mahboubkhah ${ }^{2}$, Kağan Koray Ayten ${ }^{3}$, Gürkan Kalınay ${ }^{4}$, Alireza Nemati Gendeshmin ${ }^{5}$ \\ 1*Erzurum Teknik Üniversitesi, Mühendislik Fak., Elektrik Elektronik Müh. Böl., Erzurum, Türkiye, (ORCID: 0000-0002-2181-5386), ahmetdumlu@erzurum.edu.tr \\ ${ }^{2}$ Tebriz Üniversitesi, Makine Mühendisliği Fakültesi, Makine Müh. Böl., Tebriz, İran (ORCID: 0000-0003-0275-4837), mahboobkhah@tabrizu.ac.ir \\ ${ }^{3}$ Erzurum Teknik Üniversitesi, Mühendislik Fak, Elektrik Elektronik Müh. Böl., Erzurum, Türkiye, (ORCID: 0000-0002-8933-612X), kagan.koray@erzurum.edu.tr \\ ${ }^{4}$ Erzurum Teknik Üniversitesi, Mühendislik Fak, Elektrik Elektronik Müh. Böl., Erzurum, Türkiye, (ORCID: 0000-0002-2362-4188), gurkan.kalinay@erzurum.edu.tr \\ ${ }^{5}$ Tebriz Üniversitesi, Makine Mühendisliği Fakültesi, Makine Müh. Böl., Tebriz, İran (ORCID: 0000-0002-8579-4588), alirezanege.1404@gmail.com
}

(International Conference on Design, Research and Development (RDCONF) 2021 - 15-18 December 2021)

(DOI: 10.31590/ejosat.1039979)

ATIF/REFERENCE: Dumlu, A., Mahboubkhah, M., Ayten, K. K., Kalınay, G. \& Gendeshmin, A. N. (2021). Paralel Kinematik Yapıya Dayalı 5-DOF FDM Yazıcı Tasarımı ve İmalatı. Avrupa Bilim ve Teknoloji Dergisi, (32), 754-760.

$\ddot{O} \mathbf{z}$

Bu çalışmada, 5 serbestlik derecesine sahip yeni bir 3 boyutlu (3B) yazıcının matematiksel analizi ve tasarımı gerçekleştirilmiştir. Tasarlanan sistem sayesinde, çok eksenli 3B yazıcı mekanizmalarına yeni bir konsept kazandırılmış ve böylece eklemeli imalat (AM) süreçlerinde parça kalitesini iyileştirilmesi hedeflenmiştir. Öncelikle sistemin kinematik analizi vektör cebri kullanılarak elde edilmiş ve sistem kısıtlamalarını dikkate alınarak yazıcının çalışma uzayı belirlenmiştir. Ardından tasarlanan sistemin mekanik ve elektriksel bileşenleri hakkında detaylı bilgiler verilerek tüm sistemin çalışma prensibi sunulmuştur. Tasarım çalışmalarında elde edilen bulgulara göre önerilen sistem için gerçekleştirilen kinematik analizlerin doğru olduğu kanıtlanmış ve özellikle eklemeli imalat teknolojileri için yeni bir sistem önerilmiştir.

Anahtar Kelimeler: Eklemeli imalat, Paralel manipülator, Kinematik, Çalışma uzayı.

\section{Design and Manufacturing of a Novel 5-DOF FDM Printer Based on Parallel Kinematic Structure}

\begin{abstract}
In this study, the mathematical analysis and design of a new 3D printer with 5 degrees of freedom was carried out. Thanks to the developed system, a new concept has been brought to the multi-axis 3D printer mechanisms and thus, it is aimed to improve the part quality in additive manufacturing (AM) processes. First of all, the kinematic analysis of the system was obtained using vector algebra and the work space of the current printer was determined by considering the system constraints. Then, by giving detailed information about the mechanical and electrical components of the designed system, the working principle of the whole system is presented. According to the findings obtained in the studies, the kinematic analyzes performed for the proposed system proved to be correct and a new system was proposed especially for additive manufacturing technologies.
\end{abstract}

Keywords: Additive manufacturing, Parallel manipulator, Kinematics, Workspace.

\footnotetext{
*Sorumlu Yazar: ahmetdumlu@erzurum.edu.tr
} 


\section{Giriş}

Eklemeli imalat teknolojisi The Economist dergisinin Nisan2012' de yayınlanan makalesine göre üçüncü sanayi devriminin bir parçası olarak ilan edilmiş ve böylece imalat endüstrisinde devrim yaratarak hem literatür için hem de sanayi için yoğun bir ilgi uyandırmıştır (Lin, 2018; Achim, 2019). Özellikle karmaşık geometrilere sahip ürünlerin eklemeli imalat teknolojisi sayesinde üretilebilmesi nedeniyle söz konusu teknolojiyi daha da iyileştirebilmek için literatürde birçok çalışmaya rastlanmaktadır. Burada iyileştirmeden kastedilen unsurlar, üretilecek olan ürünün mukavemetini ve dalgalı yüzey kalitesini artırmak ve aynı zamanda üretim süresinin kısaltmak olarak sıralanabilmektedir. Bununla birlikte, geleneksel 3 doğrusal serbestlik derecesine sahip takım tezgâhlarında veya yazıcılarda herhangi bir iş parçasının üretilebilmesi için destek adı verilen parçalardan yararlanılmakta ve dolasıyla bu parçalar üretim maliyetini artırmaktadır. Yukarıda sıralan dezavantajların önüne geçebilmek için son yıllarda eklemeli üretim teknolojilerinde kullanılan klasik 3 eksenli sistemler yerine daha yüksek serbestlik derecesine veya farklı kinematik yapılara sahip sistemler tasarlanmaktadır. Yapılan bir araştırmaya göre çok eksenli paralel kinematik yapıya sahip robotik sistemlerin eklemeli imalat teknolojilerinde kullanılması durumunda, özellikle karmaşık geometriye sahip parçaların üretilebilmesine olanak sağladığı ve kısıtlamaların önüne geçilebileceği ifade edilmiştir (Pınar, 2019).

Paralel kinematik yapıya sahip olan mekanizmalar, kartezyen sistemlere göre daha yüksek doğruluğa ve işleme hızına sahip olmaları nedeniyle özellikle eklemeli imalat teknolojileri için yapılan birçok tasarım çalışmasında tercih edilmişlerdir. Literatür çalışmaları incelendiğinde özellikle farklı paralel kinematik yapıya sahip sistemlerin $\mathrm{Z}$ eksenlerinde kazandırılan dönme hareketi sayesinde söz konusu sistemler 4 serbestlik derecesine yükseltilmiş ve böylece parça üretim zamanının kısaltılabilmiştir. (Wei, 2017; Jun, 2004; Clavel, 1987; Xie, 2016; Pierrot, 1999; Company, 2002; Krut, 2004; Nabat, 2005; Krut, 2006; Mehran, 2009). Yapılan bir başka çalışmada ise Delta tipi paralel kinematik yapıya sahip bir sistemin X eksenine dönme kabiliyeti kazandırılmış ve böylece sistemin hareket kabiliyeti artırılabilmiştir (Mehran, 2009).

$\mathrm{Bu}$ çalışmada yukarıda ifade edilen çalışmalardan ve literatürden farklı olarak hem $\mathrm{X}$ eksenine hem de $\mathrm{Z}$ eksenine kazandırılan dönme hareketleri sayesinde 5 serbestlik derecesine yükseltilmiş yeni bir 3B yazıcının konsept tasarımı hakkında bilgiler verilmiştir. Önerilen sistemin $X$ ve $Z$ eksenlerine kazandırılan dönme hareketi sayesinde parça yüzeyine paralel kavisli katmanların oluşturulabilmesi amaçlanmış ve bu sayede klasik sistemlerin aksine üretim sürecinde destek parçalarına ihtiyaç duyulmaması hedeflenmiştir. Söz konusu hedefe ulaşabilmek için öncelikle önerilen sistemin kinematik analizi vektör cebri kullanılarak detaylı bir şekilde sunulmuştur. CATIA software üzerinden yapılan simülasyonlarla sisteme ait çalışma uzayı belirlenmiştir. CATIA software üzerinden yapılan testlerde sistem için yapılan kinematik analizlerin doğruluğu kanıtlanmıştır. Ayrıca sisteme ait Jacobian matrisini belirleyebilmek için bu çalışmada hız kinematik analizi hakkında bilgiler de sunulmuştur.

Tasarım çalışmalarına başlanan sistemin hem mekanik hem de elektriksel bileşenleri bu çalışmada tanıtılmış olup tüm sistemin konsept tasarımı ayrıntılı bir şekilde sunulmuştur. $\mathrm{Bu}$ çalışmanın literatüre asıl katkısı klasik 3B yazıcıların aksine e-ISSN: 2148-2683 üretim maliyetlerini azaltabilecek, daha hassas ve daha yüksek hızda çalışabilen yeni bir paralel kinematik yapıya sahip 3B yazıcının konsept tasarımını hakkında bilgiler vermek ve sistemin doğru bir şekilde çalışabilmesi için gerekli olan tüm matematiksel analizleri sunmaktır.

\section{5-Eksenli 3D Yazıcının Konsept Dizaynı}

Tasarımı gerçekleştirlen 3D yazıcı sistemi Şekil 1a, b' de gösterildiği gibi iki adet $\mathrm{PR}(\mathrm{Pa}) \mathrm{R}$ ve iki adet $\mathrm{PR}(\mathrm{Pa}) \mathrm{U}$ olmak üzere toplamda dört adet kinematik zincirle birbirine bağlanan sabit ve hareketli bir platformdan oluşmaktadır. Burada $\mathrm{P}, \mathrm{R}, \mathrm{Pa}$ ve $U$ sirasıyla prizmatik, döner, parallelogram ve üniversal mafsalları temsil etmektedir. Bu kinematik zincirlerin ana bileşeni düzlemsel dört barlı paralelkenar yapısındadır. $\mathrm{Bu}$ yapılar, birbirinden bağımsız doğrusal ray sistemine monte edilmiş dört adet araba vasitasıyla manipüle edilmektedir. Paralelkenar yapısını oluşturmak için sistem üzerinde yer alan arabaların her biri küresel mafsallar yardımı ile her bir linke ayrı ayrı bağlanmaktadır. Diğer uçta, ikinci ve üçüncü kol için mafsallar hareketli platforma küresel mafsallar vasitasıyla, birinci ve dördüncü kol için ise mafsallar dolaylı olarak hareketli platforma bağlanmaktadır. Her konnektör, döner mafsal ile hareketli platforma bağlanır. Mevcut manipülatör için, hareketli platform, 3-DOF öteleme ve $x$-yönünde 1-DOF dönme hareketliliğine sahiptir (bkz. Şekil 1a, b). Z yönü için gereken dönme hareketliliği, bir döner tabla aracılığıyla sağlanmaktadır.

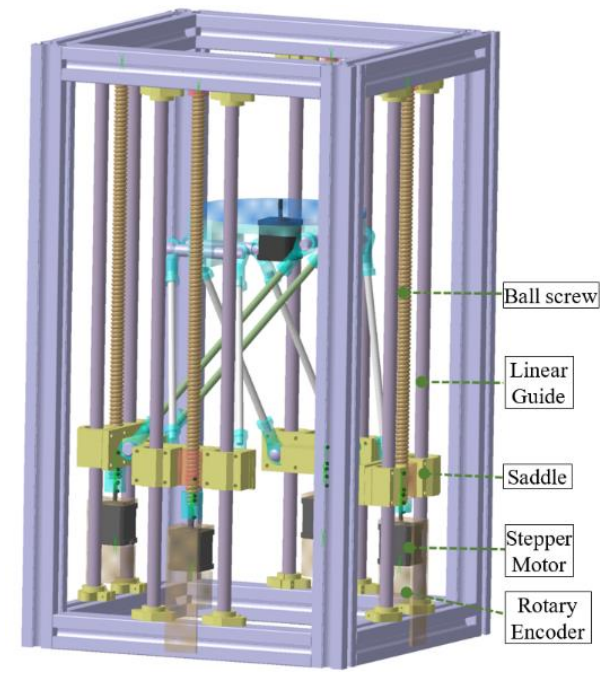

Şekil 1a. Önerilen 5 DOF paralel mekanizmasının yapısı

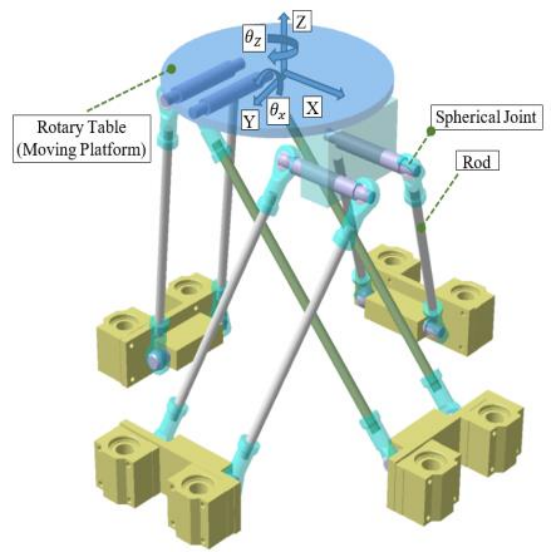

Şekil 1b. Önerilen 5 DOF Paralel Mekanizmasının Bağlantıları ve Hareketli Platformu 
Şekil 2' de CATIA yazılımı kullanılarak tasarlanan ve modellenen paralel mekanizmanın bileşenlerinin konfigürasyonu açıkça gösterilmiştir. Sistemin tüm bileşenleri bu yazılımın montaj ara yüzünde tasarlanmış ve kurulmuştur. Sisteme ait önemli boyutlarından bazıları ise Şekil 3 'te gösterilmiştir.
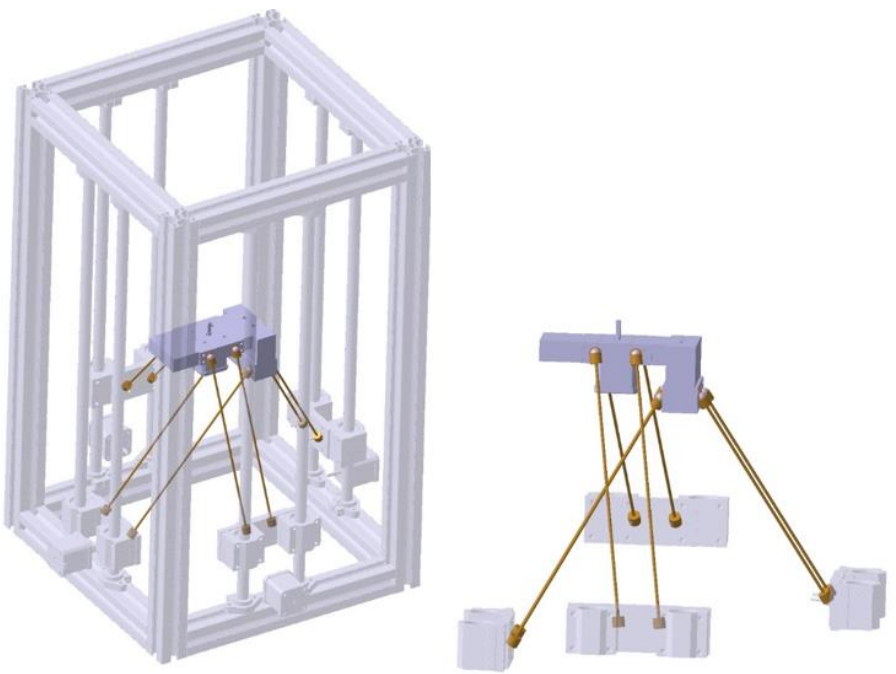

Şekil 2. 5 DOF 3D yazıcının konfigürasyonu

\section{1. Önerilen 5-DOF 3D Yazıcının Matematiksel Modellenmesi}

Bu bölümde sistem için yapılan kinematik ve çalışma uzayı analizleri hakkında detaylı bilgiler sunulmuştur. Öncelikle, önerilen sistemin katı cisim modellemesi dikkate alınarak vektör yaklaşımı ile ters kinematik analiz gerçekleştirilmişstir. Ardından, elde edilen kinematik denklemler ve sistem kısıtlamaları dikkate alınarak söz konusu mekanizmanın çalışma uzayı analizi gerçekleştirilmiştir. Son olarak mekanizmaya ait hız ve ivme kinematik analizleri üzerinde çalışmalar yapılmıştır.

\subsection{1. Önerilen 5-DOF 3D Yazıcının Ters Kinematiği}

Ters kinematik analiz hareketli platformun konum ve yönelim değerleri verildiğinde, hareketli platformu bu konum ve yönelim değerlerine getirecek olan bağların açısal konumlarını hesaplama işlemidir. Sistemi doğru bir şekilde kontrol edebilmek için ve aynı zamanda sisteme ait dinamik modeli ortaya koyabilmek için bu kinematik analizin doğru bir şekilde ortaya koyulması gerekmektedir. Literatürde farklı tipteki paralel mekanizmaların kinematik analizleri için farklı metotlardan yararlanılmaktadır. Bunlar, Denavit-Hartenberg metodu, vektör cebri metodu, geometrik yaklaşım ve Bezout yöntemlerdir. Ayrıca son yıllarda kinematik analiz için genetik ve Nelder-Mead algoritmalarından da yararlanılmaktadır.

$\mathrm{Bu}$ çalışmasında mekanizmanın ters kinematik analizi için vektör cebri yönteminden yararlanılmıştır. Söz konusu analizi gerçekleştirebilmek için Şekil 4'te sisteme ait bir vektör diyagramı gösterilmiştir. Mekanizmadaki kinematik zincirlerin benzerliğinden dolayı bunlardan sadece bir tanesi ' $i$ ' indeksi ile gösterilmiştir. Şekil 3' te görüleceği üzere Global koordinat sisteminin orijini $\{\mathrm{O}\}$ olup bu koordinat sisteminin bileşenleri $x_{o}, y_{o}$ ve $z_{o}$ ile tanımlanmıştır. Global koordinat sisteminin orijini ile her prizmatik eklemin rayının başlangıcına birleştirilen vektör $\boldsymbol{a}_{\boldsymbol{i}}$ ile temsil edilirken, rayın yerel başlangıç noktası, araba üzerindeki $i$ prizmatik eklemine bağlayan vektör $\boldsymbol{d}_{\boldsymbol{i}}$ ile gösterilmiştir. Şekilde görülen $\boldsymbol{l}_{\boldsymbol{i}}$ vektörünün büyüklüğü ise $i$. bağlantı kolunun uzunluğuna eşittir. Ayrıca $\boldsymbol{c}_{\boldsymbol{i}}$ vektörü ise, küresel eklemlerin orta noktasından başlayıp konektörün döner ekseninde biten $i$. konektöre bağlı bir vektördür. Bununla birlikte, $i=2,4$ için, mekanizmanın yapısı gereği $\boldsymbol{c}_{\boldsymbol{i}}$ vektörü 0 ' a eşit olmak zorundadır. Şekil 4' de tanımlanan, $\boldsymbol{b}_{\boldsymbol{i}}$ vektörü, hareketli platformun $\{\mathrm{P}\}$ merkezine sabitlenmiş, yerel çerçeveye göre paralelkenarların sonunun pozisyonunu ifade eden bir vektör olarak tanımlanmaktadır. Tüm kinematik ilişkilerin sabit platforma bağlı global çerçeveye $\{\mathrm{O}\}$ göre tanımlanmaktadır.

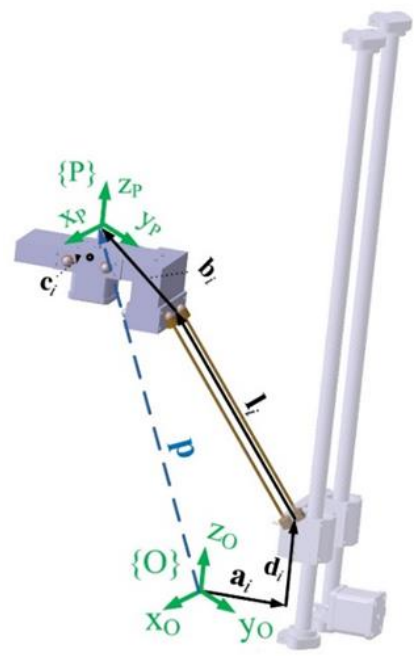

Şekil 3. Sistemin kinematik modellemesi için vektör notasyonu

Şekil 4 dikkate alınarak $i$. kinematik zincir için vektörel eşitlik Denklem 1'deki gibi ifade edilebilmektedir.

$$
o_{\boldsymbol{p}}+{ }_{P}^{o} \boldsymbol{R}_{i}^{P} \boldsymbol{b}={ }_{i}^{o} \boldsymbol{a}+{ }_{i}^{o} \boldsymbol{d}+{ }_{i}^{o} \boldsymbol{l}+{ }_{i}^{o} \boldsymbol{c}
$$

$\mathrm{Bu}$ denklemde $\boldsymbol{b}_{i}$ vektörü global koordinat sistemine göre tanımlamak için aşağıda verilen dönüşüm ifadesi kullanılması gerekmektedir.

$$
{ }_{i}^{o} \boldsymbol{b}={ }_{P}^{o} \boldsymbol{R}_{i}^{P} \boldsymbol{b}
$$

Denklem 2'de ifade edilen ${ }_{p}^{o} \boldsymbol{R}$, rotasyon matrisi olup sistemin mekanik yapısından dolayı Denklem 3' de ifade edildiği gibi sadece $\boldsymbol{x}$ yönünde tanımlanmıştır.

$$
{ }_{P}^{o} R=R_{X}(\theta)=\left[\begin{array}{ccc}
1 & 0 & 0 \\
0 & \cos (\theta)_{x} & -\sin (\theta)_{x} \\
0 & \sin (\theta)_{x} & \cos (\theta)_{x}
\end{array}\right]
$$

Denklem 1' de yer alan ${ }_{i}^{\boldsymbol{o}} \boldsymbol{d}$ ve ${ }_{\boldsymbol{i}}^{\boldsymbol{o}} \boldsymbol{c}$ vektörleri her zaman birbirine paraleldir. Bu nedenle $\widehat{\boldsymbol{d}}_{\boldsymbol{\imath}}, \boldsymbol{d}_{\boldsymbol{i}}$ vektörünün birim vektörü olması sebebiyle Denklem 1, Denklem 4'teki gibi yeniden yazilabilmektedir.

$$
\left(\boldsymbol{p}+\boldsymbol{b}_{\boldsymbol{i}}-\boldsymbol{a}_{\boldsymbol{i}}-c_{i} \widehat{\boldsymbol{d}}_{\boldsymbol{\imath}}\right)-\boldsymbol{L}_{\boldsymbol{i}}=d_{i} \widehat{\boldsymbol{d}}_{\boldsymbol{\imath}}
$$

Burada $c_{i}$ ve $d_{i}$, sırasıyla $\boldsymbol{c}_{\boldsymbol{i}}$ ve $\boldsymbol{d}_{\boldsymbol{i}}$ vektörlerinin büyüklüğünü temsil etmektedir. $\boldsymbol{L}_{\boldsymbol{i}}$ vektörü $l_{i}$ ile gösterilmekte ve değeri bilinmemektedir. $\mathrm{Bu}$ durumda, yukarıda verilen denklemin sol tarafı, merkezi $\boldsymbol{p}+\boldsymbol{b}_{\boldsymbol{i}}-\boldsymbol{a}_{\boldsymbol{i}}-c_{i} \widehat{\boldsymbol{d}}_{\boldsymbol{\imath}}$ ve yarıçapı $l_{i}$ olan bir küreyi ve aynı zamanda Denklem 4'ün sağ tarafi, orijinden ve $\boldsymbol{d}_{\boldsymbol{i}}$ boyunca geçen bir çizgiyi temsil etmektedirler. Bu nedenle, Denklem 4'ü çözmek demek, uzayda bilinen bir küre ile bir doğrunun kesişimini elde etmeye eşdeğer anlamına gelmektedir. Yukarıda belirtilen eşdeğerlilikler kullanılarak $d_{i}$ aşağıdaki gibi elde edilebilmektedir. 
$d_{i}=-c_{i}+\widehat{d}_{i}^{T}\left(p+b_{i}-a_{i}\right) \pm \sqrt{l_{i}^{2}-\left(p+b_{i}-a_{i}\right)^{T}\left(I_{3 \times 3}-\widehat{d_{i}} \widehat{d}_{i}^{T}\right)\left(p+b_{i}-a_{i}\right)}$

Vektör analizi ile elde edilen Denklem 5 yardımıyla mekanizmanın konum ve yönelim değerleri tanımlandığında, mekanizmayı bu konum ve yönelim değerlerine getirecek olan $d_{i}$ uzunluğu hesaplanabilmektedir.

\subsection{2. Önerilen 5-DOF 3D Yazıcının Çalışma Uzayı}

Bilindiği üzere, seri bağlı üç dikey eksene (X, Y, Z) sahip genel takım tezgahları için, çalışma uzayını belirlemek çok kolaydır. Fakat eksen sayısının arttırılması durumunda ortaya çıkan bazı kısıtlamalar nedeniyle çalışma uzayının belirlenmesinde bazı problemlerle karşılaşılmaktadır. Benzer şekilde, paralel yapıya sahip takım tezgâhlarında da sabit bir ortogonal eksen olmaması nedeniyle çalışma uzayını belirlemede bazı güçlüklerle karşılaşılmaktadır. Paralel mekanizmanın çalışma uzayı, kinematik parametreler veya yapının kısıtlamaları dikkate alınarak elde edilmektedir. Bu nedenle tüm kısıtlamalar dikkate alınarak oluşturulacak olan çalışma uzayı düzgün bir geometrik şekle sahip değildir. Bu düzgün olmayan geometrik şekilden dolayı paralel mekanizmaların kullanılması çalışma uzayı açısından bir dezavantaj olarak ortaya çıkmaktadır. Bu dezavantajı minimuma indirebilmek için, sistem için en iyi çalışma aralığının belirlenmesi gerekmektedir. Literatürde farklı tipteki paralel mekanizmalar için yapılan çalışma uzayı analizlerinde genellikle mekanizmanın kısıtlamaları dikkate alınarak optimizasyon yöntemlerinden yararlanılmıştır.

$\mathrm{Bu}$ çalışma kapsamında tasarlanan paralel mekanizmanın çalışma uzayını elde etmek için kısıtlamaların göz önünde bulundurulduğu bir optimizasyon algoritması geliştirilmiştir. $\mathrm{Bu}$ yöntemde geliştirilen algoritma, çalışma alanındaki noktanın konumuna göre makinenin tüm çalışma alanını tarar ve ardından fiziksel kısıtlamaları veya paralel takım tezgahlarının limitini kontrol ederek çalışma uzayının her noktasını doğrulamaktadır. Genel olarak, çalışma uzayı analiz algoritması üç ana aşamaya ayrilabilir:

i. Çalışma uzay aralığını bulmak için arama algoritması

ii. Ters kinematiği dönüştürme işlemi

iii. Fiziksel kısıtlamaları veya makine limitini test etme

Çalışma alanı analiz algoritmasında, arama algoritmasından hareketli platform pozisyonu (konum ve oryantasyon) sağlandıktan sonra ters kinematiğin dönüştürülmesi, makinenin fiziksel sınırlamalarının test edilmesi için temel pozisyon sağlamaktadır. Çalışma uzayı $\mathrm{x}$ - y düzlemlerine veya $\mathrm{z}$ boşlukları sabit yatay bölümlere ayrılarak tarama işlemlerine başlanır, ardından düzlemin tüm noktaları tarandıktan sonra bir sonraki düzlemin tarama işlemlerine geçilir. Bu algoritma kutup - silindir koordinat sistemine göre çalışmaktadır. Bu mekanizmada dikkate alınan kısıtlamalar ve fiziksel sınırlamalar aşağıda ifade edilmiştir.

\section{a) Ray üzerinde yer alan arabanın hareket kısıtlaması:}

Ray üzerinde bulunan arabanın hareket aralığı izin verilen aralıkta ise, dikkate alınan noktalar çalışma uzayı içinde olacaktır. Bu sınır Denklem 6'daki gibi ifade edilmektedir.

$$
\boldsymbol{d}_{\min } \leq \boldsymbol{d}_{\boldsymbol{i}} \leq \boldsymbol{d}_{\max }
$$

\section{b) Ray ile hareketli platform arasındaki kısıtlama:}

Tasarlanan mekanizmada, analiz edilmesi ve kaçınılması gereken kısıtlama açılardan ilki, ray ile hareketli platformun çarpışma olasılığında yer alan açıdır. Bu açı, hareketli platform yapısı ile ray arasında çarpışma olmayacak şekilde kayar eklem boyunca farklı araba koşulları için elde edilebilir ve bu durum Şekil 5'te gösterilmiştir. Hareketli platform ile rayın çarpışmasını önlemek için gerekli koşul Denklem $7^{\prime}$ deki gibi ifade edilmektedir.

$$
\boldsymbol{\theta}_{\text {critical }} \leq \boldsymbol{\gamma}
$$

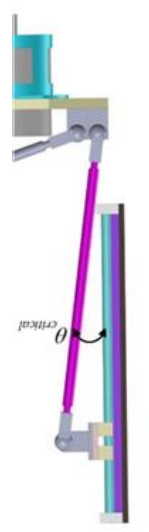

Şekil 4. Hareketli platform ve ray arasındaki açı kısıtlaması

\section{c) Eklem açılarının kısıtlaması:}

Dikkate alınması gereken bir sonraki açı $\theta_{j}$ 'dir. Bu açı, hareketli platforma bağlı bacakların sabit ray ile yapabileceği yanal maksimum açıyı temsil etmektedir ve Şekil 5'da gösterilmiştir. $\mathrm{Bu}$ açı için izin verilen maksimum değer 30 derecedir. Diğer bir deyişle:

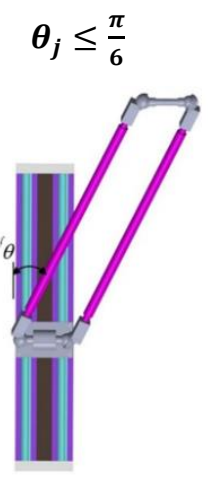

Şekil 5. İzin verilen yanal maksimum açı kısıtlaması

\section{d) Hareketli platforma bağlı bacaklar ile platform arasındaki kisitlama:}

Önerilen mekanizmada, Şekil 5'de gösterildiği gibi, hareketli platforma bağlı bacak uç kısmının bağlı olduğu platforma çarpışma olasılığı vardır. $\mathrm{Bu}$ nedenle çalışma uzayı optimizasyonu yapılırken, belirtilen bu açının küçük bir değerde seçilmesi gerekmektedir. 


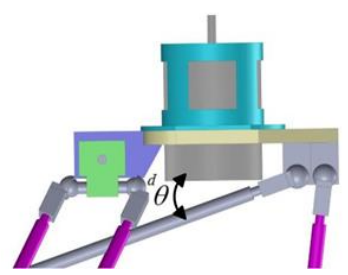

Şekil 6. Hareketli platform kısitlaması

Yukarıda sıralanan kısıtlamalar dikkate alınarak yapılan optimizasyon çalışmasında elde edilen çalışma uzayı aşağıda verilen Şekil 7'de gösterilmiştir.

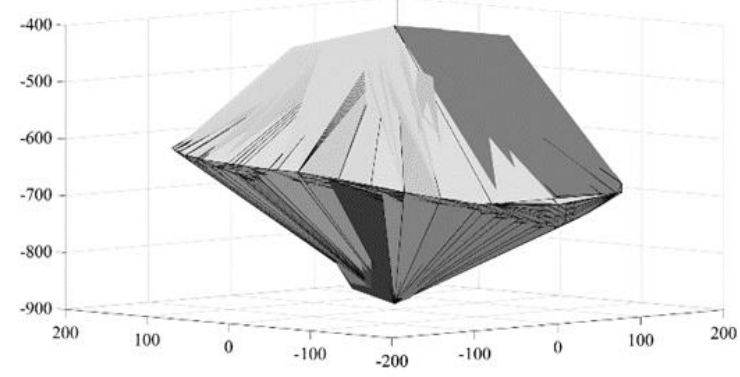

Şekil 7. Tasarlanan sistemin çalışma uzay alanı

\subsubsection{5-DOF 3D Yazıcının Hız, Kinematik Analizi}

Mekanizmanın hareketli platformuna ait hız vektörünü $\dot{\boldsymbol{p}}$ ' yi tanımlayabilmek için, Denklem 4'ün türevinin zamana göre alınması gerekmektedir.

$$
\dot{\boldsymbol{p}}+\dot{\theta} \hat{\imath} \times \boldsymbol{b}_{i}=\dot{d}_{\imath} \widehat{\boldsymbol{d}}_{\boldsymbol{l}}+\boldsymbol{\omega}_{l i} \times \boldsymbol{I}_{\boldsymbol{i}}
$$

$\mathrm{Bu}$ denklemde $\dot{\theta}$, hareketli platformun açısal hız genliğidir. Denklem 6'nın her iki tarafının $\boldsymbol{I}_{\boldsymbol{i}}$ vektörü ile skaler çarpım yapılması durumunda, Denklem 7 elde edilmektedir.

$$
\dot{d}_{\iota}=\frac{I_{i}}{\widehat{d_{l} I_{i}}} \cdot \boldsymbol{p}+\frac{\left(\hat{\imath} \times b_{i}\right) \cdot I_{i}}{\widehat{d_{l}} I_{i}} \cdot \dot{\theta}
$$

Böylece denklem 7 kullanılarak hareketli platformun açısal formdan doğrusal forma dönüştüren hız kinematiği ile ilgili matris gösterimi Denklem 8'deki gibi elde edilmektedir.

$$
\left[\begin{array}{c}
\dot{d}_{1} \\
\vdots \\
d_{4}
\end{array}\right]=\left[\begin{array}{cc}
\frac{I_{1}^{T}}{\widehat{d_{1}} I_{1}} & \frac{\left(b_{1} \times I_{1}\right) \hat{\imath}}{\widehat{d_{1}} \cdot I_{1}} \\
\vdots & \vdots \\
\frac{I_{4}^{T}}{\widehat{d_{4}} \cdot I_{4}} & \frac{\left(b_{4} \times I_{4}\right) \widehat{\imath}}{\widehat{d_{4} \cdot I_{4}}}
\end{array}\right]\left[\begin{array}{c}
\dot{\boldsymbol{p}} \\
\dot{\theta}
\end{array}\right]=J\left[\begin{array}{l}
\dot{\boldsymbol{p}} \\
\dot{\theta}
\end{array}\right]
$$

Denklem 8' de ifade edilen $\boldsymbol{J}$, sisteme ait Jabobian matrisi temsil etmektedir

\subsubsection{5-DOF 3D Yazıcının İvme Kinematiği}

Hareketli platformun ivme ifadesini elde edebilmek için Denklem 6'nın türevi alınması gerekmektedir:

$$
\ddot{p}+\ddot{\theta} \hat{\imath} \times b_{i}+\dot{\theta}^{2} \hat{\imath} \times\left(\hat{\imath} \times b_{i}\right)=\ddot{d}_{\iota} \widehat{d}_{\imath}+\dot{\omega}_{l \iota} \times I_{i}+\omega_{l i} \times\left(\omega_{l i} \times I_{i}\right)
$$

Söz konusu bu denklemin her iki tarafının $\boldsymbol{I}_{\boldsymbol{i}}$ vektörü ile noktasal çarpımının yapılması durumunda sisteme ait prizmatik mafsalların ivme ifadesi aşağıdaki gibi elde edilmektedir:

$$
\ddot{d}_{\imath}=\frac{1}{\widehat{d_{l} \cdot I_{i}}}\left\{\left(\ddot{\boldsymbol{p}}+\ddot{\theta} \hat{\imath} \times b_{i}+\dot{\theta}^{2}\left(\left(\hat{\imath} b_{i}\right) \hat{\imath}-b_{i}\right) I_{i}-\left(\omega_{l i} . I\right)^{2}+\left(\left\|\omega_{l i}\right\| l_{i}\right)^{2}\right\}\right.
$$

\subsection{5-DOF 3D Yazıcının Elektriksel Alt Bileșenlerinin Tasarımı}

Tasarlanan sistemde bulunan rayların hareket ettirilmesi için step motorlardan yararlanılmıştır. Bu step motorlarının belirli bir adım miktarında hareket ettirilebilmesi için 4 katmanlı hassas bir sürücü kartının yapımı gerçekleştirilmiştir. Öncelikle gerekli komponentler belirlenerek baskı devrenin çizimi gerçekleştirilmiştir. Baskı devre çizimi için Altium designer (student version) kullanılmıştır. Baskı devre kartı 4 katmanlı tasarlanmıştır. Güç ve topraklama için ara katmanlar kullanılmıştır. Güç elektroniği elemanlarını ve dijital elektronik elamanları adalama yöntemi ile ayrılmıştır. Topraklama adaları filtrelenerek bağlanmıştır, bu şekilde güç elemanlarında gelen gürültülerin dijital elektronik elemanlarına etkisi azaltılmıştır. Besleme girişi, kısa devreye ve aşırı voltaja karşı TVS diyot ve smd sigorta ile korunmuştur. Baskı devre çizimleri Şekil 8' daki resimlerde görülmektedir.

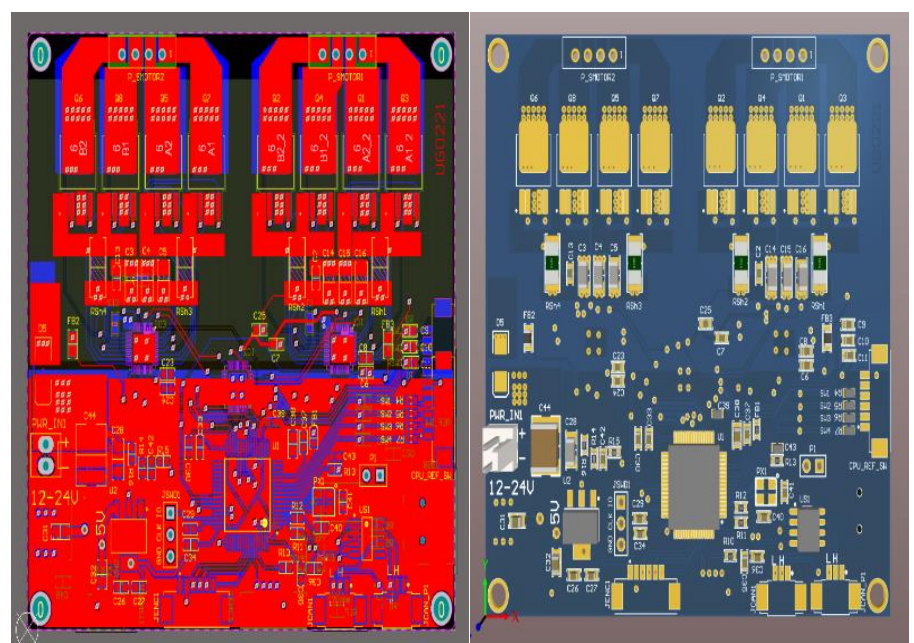

Şekil 8. Tasarlanan sürücü kartına ait baskı devre çizimleri

MOSFET dizilerinde oluşan sıcaklığın dağıtılması için geniş haltama ve vialama tekniği uygulanmıştır. MOSFET dizilerinin sürülmesi için entegre sürücüler kullanılmıştır. Haberleşme hatları ve dijital girişler filtrelenerek, gürültü etkileri azaltılmıştır. Elektronik komponentler kurşunsuz olarak seçilmiştir. Baskı devre kartı üzerindeki pedler altın daldırma yöntemiyle üretilmesi sağlanmıştır. $\mathrm{Bu}$ şekilde iletkenlik artırılarak, oksidasyonun azaltılması sağlanmıştır. Baskı devre üretimini tamamlanmasına müteakip komponent tedariki gerçekleştirilmiştir. Dizgi süreçleri, sıvı lehim ve baskı devre şablonu (stencil) kullanılarak gerçekleştirilmiştir. Sistemde kullanılmak üzere 4 adet sürücü kartının dizgisi gerçekleştirilmiştir. Dizgisi tamamlanmış sürücü kartı Şekil 9' daki resimde görülmektedir.

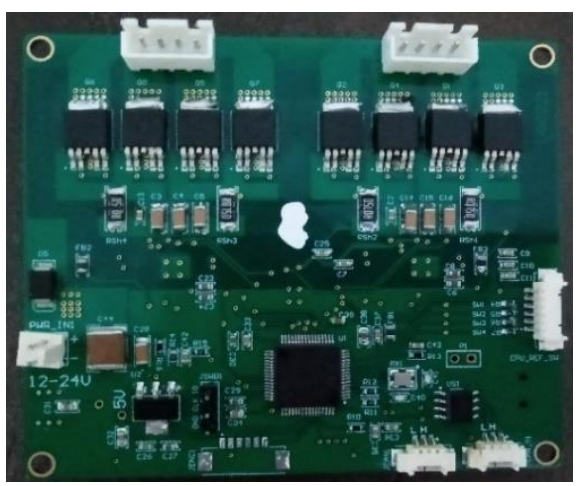

Şekil 9. Dizgisi tarafımızdan yapılmış sürücü kartı 
Sürücü kart iki adet step motoru sürebilecek donanıma sahiptir. Kart üzerinde STM32f405RBT6 serisi ARM Cortex M4 168MHz işlemci bulunmaktadır. Motor sürme yazılımları bu işlemci içerisinde koşturulmaktadır. Motor bobinleri üzerinden gecen akım, toleransı düşük shunt dirençler ile ölçülebilmektedir. Her bir adım motor, 4 adet N-P MOTFET dizisi barındıran anahtarlama elemanı ile akım geri beslemesi alınarak sürülmektedir. Sürücü, akım kontrollü mikro adım sürme özelliğine sahiptir. Tasarlanan sürücü, 256 mikro adıma kadar pozisyonlama imkânı vermektedir. $\mathrm{Bu}$ şekilde 1,8 derece/adım özelliğine sahip adım motorun, bir tur dönüşü 51200 adım çözünürlükle kontrol edilebilmektedir. Sürücü üzerinde iki adet SPI (Serial Peripheral Interface) enkoder bağlantı birimi bulunmaktadır. Haberleşme için USB, USART ve CAN (Controller Area Network) bağlantı birimleri kullanılabilmektedir. Hareket başlangıç ve son konumlarının belirlenmesi için 7 adet anahtar okuma girişi bulunmaktadır. Sürücü kartı, 12-24V giriş voltaj aralığında çalışabilmekte ve 5 Ampere kadar akımı motor bobinlerine aktarabilmektedir. Sürücü yüksek tork ve hassas pozisyonlama yapabilmektedir. Sürücü, motor kontrolünde düzgün yamuk (trapezoidal) hareket profili oluşturabilmektedir. Ayrıca, ivme ve hız kontrolüne imkân vermektedir.

İşlemci yazılımları, açık kaynak STM32CubeIDE ortamında geliştirilmiş ve işlemciye yüklenmiştir. İşlemci yazılımı, motor çalışma ve tutma akımını, motor kısa devre durumunu, motor tutunma gücünü kontrol edilebilmektedir. Motor pozisyonu dijital olarak değiştirilebilmektedir. Ayrıca, motor mutlak pozisyonları okunabilmektedir. Motor başlangıç konumları, optik anahtarlardan gelen dijital sinyal belirlenebilmektedir.

Sistemde 6 adet motorun kontrolü için 3 adet sürücü kart tasarlanmıştır. Sürücüler CAN üzerinden haberleştirilmiş ve düğüm ağ (node network) yapısı oluşturulmuştur. Sürücü kartlarına konum gönderimi için USB ve CAN haberleşme ara yüzlerine sahip ayrı bir kart tasarlanmıştır. Ters kinematik hesaplamaları ve GCode ayrıştırıcı için gerekli yazılımlar, bu kart üzerinde koşturulmuştur. Bilgisayar üzerinden alınan, GCode formatındaki komutların $\mathrm{CAN}$ ağı üzerinden ilgili motorlara iletilmesi sağlanmıştır.

CAM/CAD modele ait GCODE dosyalarının 3D yazıcı sistemine aktarılması için acık kaynak Qt geliştirme ortamında görsel ara yüz programı geliştirilmiştir. Görsel ara yüz yazılımı Şekil 10' deki resimde görülmektedir.

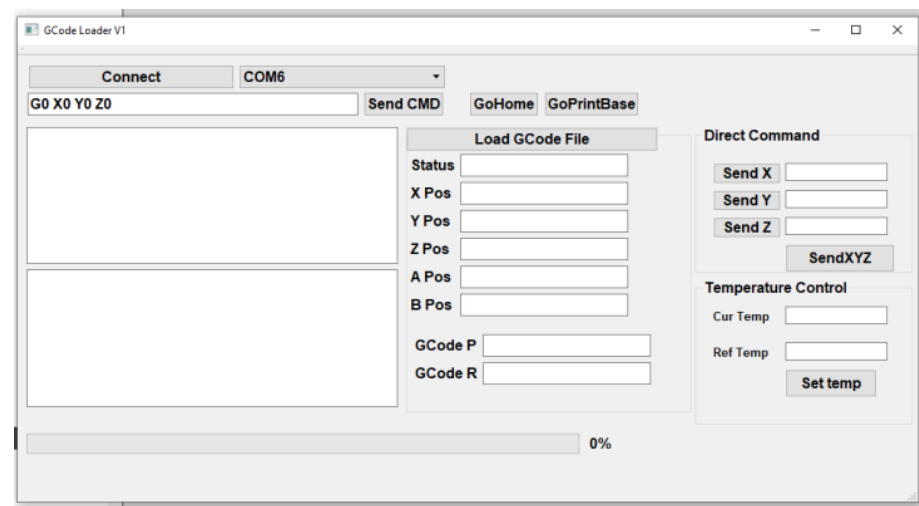

Şekil 10. Tasarlanan sürücü kartının ara yüz programı

Entegrasyon çalışmalarında, tasarlanan sürücüler mekanik sisteme entegre edilmiştir. 6 adet motorun hassas konumlandırması yapılmıştır. Kule motorlarının başlangıç pozisyonlarının belirlenmesi için 4 adet optik anahtarın montajı ve entegrasyonu yapılmıştır. Ters kinematik ve GCode ayrıştırma yazılımları devreye alınmıştır. Motor başlangıç noktaları belirlenmiş ve testleri gerçekleştirilmiştir. $\mathrm{Bu}$ pozisyonlar ev(Home) konumu olarak tanımlanmış. 3D baskı için baskı tablasını referans konumu ters kinematik hesaplamalarına göre belirlenmiş ve baskı öncesinde bu referansa gitmesi sağlanmıştır. Farklı GCode komutları test edilerek, sistem baskı için hazır hale getirilmiştir. Test işlemleriyle ilgili fotoğraf Şekil 11' de gösteriliştir.

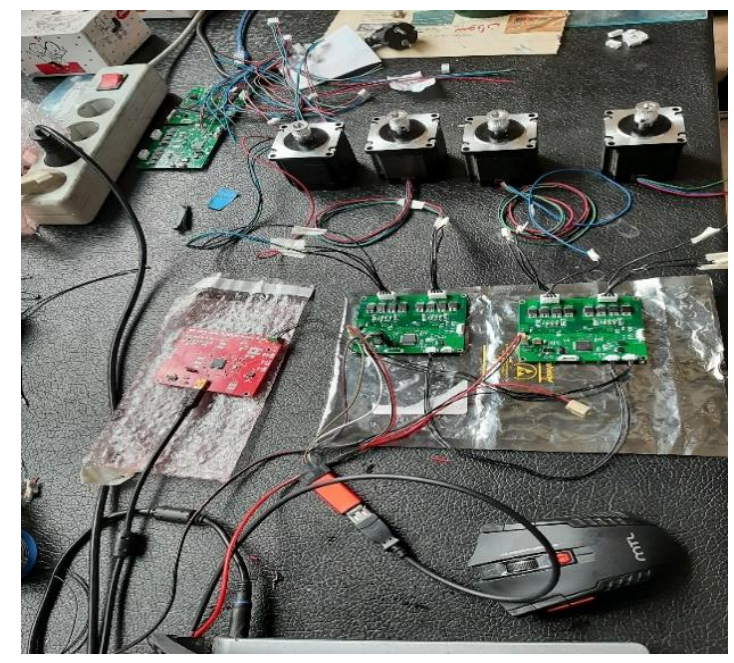

Şekil 11. Test işlemleriyle ilgili fotoğraf

\section{5-Eksenli 3D Yazıcı Sisteminin Tasarımı}

Paralel mekanizmanın modelleme ve matematiksel analizinden sonra tüm bileşenlerin yapım aşamasına geçilmiştir. Modellenen sistemin ters kinematik ve çalışma uzayı göz önüne alınarak sistemin mekanik alt bileşenlerin tasarımı gerçekleştirilmiş ve tasarlanan tüm alt bileşenlerin montajı yapılarak kalibrasyonları sağlanmıştır. Tasarlanan mekanik alt bileşenlerin resimleri ve bu bileşenler için yapılan kalibrasyon işlemleriyle ilgili resimler Şekil 12' de sunulmuştur. Tüm sistem bileşenlerinin bir araya getirilerek tasarımı tamamlana sistemin footgrafı ise şekil 13' de sunulmuştur. 

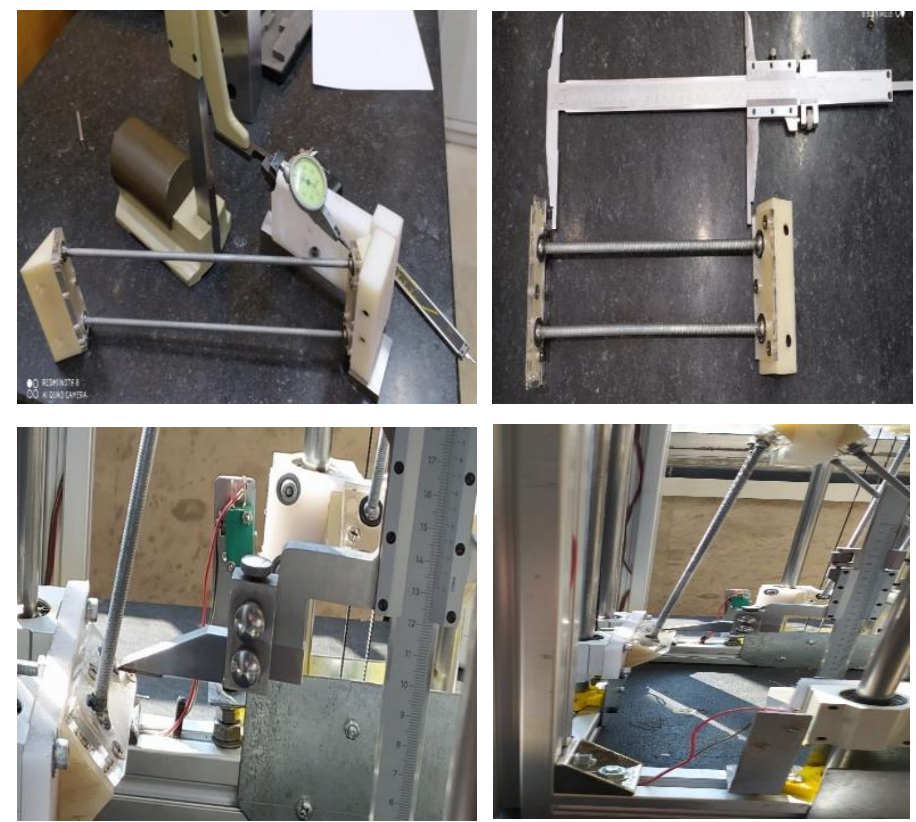

Şekil 12. Mekanik alt bileşenler ve kalibrasyon işlemleri
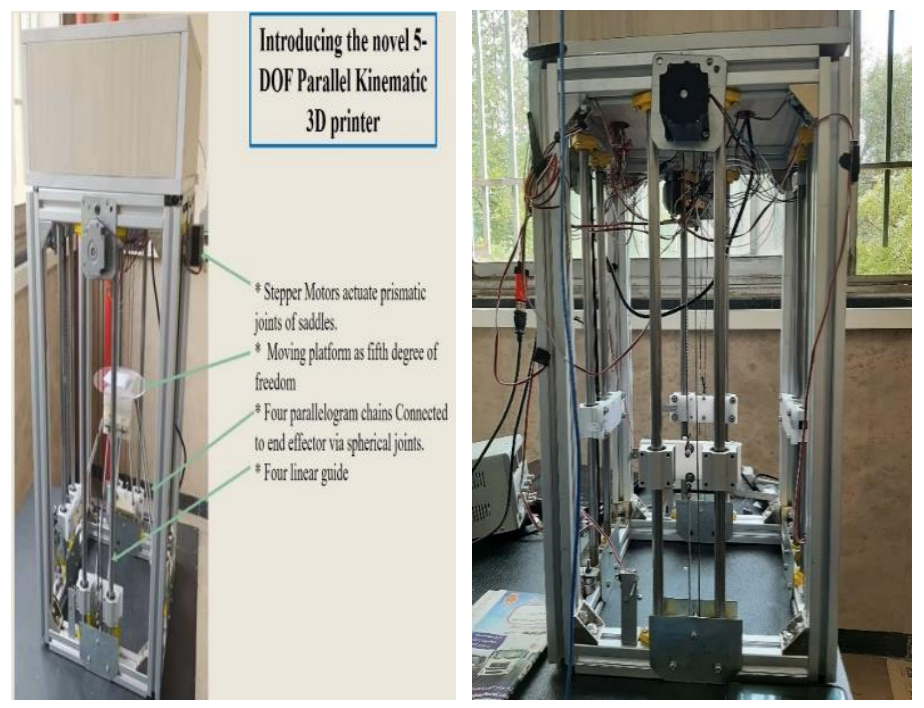

Şekil 13. Tasarlanan 5-DOF Paralel 3D Yazıcı

\section{Sonuç}

$\mathrm{Bu}$ çalışmada eklemeli imalat teknolojilerinde kullanılabilecek yeni bir 5 serbestlik derceli 3B yazıcının matematiksel analizleri ve tasarımı hakkında bilgiler sunulmuştur. Geliştirilen sistemin piyasada var olan diğer sistemlere göre en önemli özelliği serbestlik derecesinin fazla olmasıdır. $X$ ve $Z$ eksenleri ilave edilen dönme hareketi sayesinde hem parça işleme hızını atırılması amaçlanmış ve hemde üretim sırasında ihtiyaç duyulabilen destek parçaların sayısı minimize edilmesi hedeflenmiştir. Tasarlanan sistemin matematiksel analizlerinin ve tasarım için gerekli sistem alt bileşenleri hakkında bilgiler sunulan bu çalışmanın deneysel çıktıları ayrı bir çalışmayla literatürle paylaşılacaktır.

\section{Teşekkür}

Bu çalışma TÜBİTAK 119N707 nolu proje kapsamında desteklenmiştir.

\section{Kaynakça}

Lin Li, Azadeh Haghighi \& Yiran Yang. (2018). A novel 6-axis hybrid additive-subtractive manufacturing process: Design and case studies. Journal of Manufacturing Processes, (33), 150-160.

Achim Kampkera, Johannes Triebsa, Sebastian Kawolleka, Peter Ayvaza \& Steffen Hohenstein. (2019). Review on Machine Designs of Material Extrusion based Additive Manufacturing (AM) Systems. Status-Quo and Potential Analysis for Future AM, Procedia CIRP 81, 815-819.

Pinar Urhal, Andrew Weightman, Carl Diver \& Paulo Bartolo. (2019). Robot A review, Robotics and Computer Integrated Manufacturing, (59), 335-345.

Wei Ye, Yuefa Fang \& Sheng Guo. (2017). Design and analysis of a reconfigurable parallel mechanism for multidirectional additive manufacturing. Mechanism and Machine Theory, (112), 254-261.

Jun Zhang \& Frank Liou. (2004). Adaptive Slicing for a MultiAxis Laser Aided Manufacturing Process. J. Mech. Des (2004), 126(2), 254-261.

Clavel, R. (1987). Unmanned robotic delta weapon platform. WIPO patent; (WO 87/03528).

Xie, F., \& Liu, X. J. (2016). Analysis of the kinematic characteristics of a high-speed parallel robot with Schönflies motion: Mobility, kinematics and singularity. Front. Mech. Eng. (11), 135-143.

Pierrot, F. \& Company O. (1999). H4: a new family of 4-dof parallel robots. AIM'99: IEEE/ASME Int. Conf. on Adv. Intelligent Mechatronics, Atlanta, Georgia, USA, 508-513.

Company, O., Krut, S., \& Pierrot, F. (2002). Modelling of a 4 axis parallel machine for heavy parts handling. In Development methods and application experience of parallel kinematics. Proc. of the 3rd Chemnitz Parallel Kinematics Sem. PKS2002 , (16), 151-168.

Krut, S., Nabat, V., Company, O. \& Pierrot, F. (2004). A high speed robot for Scara motions. In Proceedings of IEEE ICRA: Int. Conf. on Robotics and Automation, New Orleans.

Nabat, V., Company, O., Krut, S., Rodriguez, D. O., \& Pierrot, F. (2005). Par4: Very high speed parallel robot for pick and place. In Proc. of IEEE/RSJ IROS: Int. Conf. on Intelligent Robots and Systems, Edmonton, Alberta, Canada.

Krut, S., Company, O., Nabat, V., \& Pierrot, F. (2003). Heli4: a parallel robot for scara motions with a very compact travelling plate and a symmetrical design. In Proc. of IEEE/RSJ IROS: Int. Conf. on Intelligent Robots and Systems, Beijing, China.

Mehran Mahboubkhah \& Ahmad Barari. (2019). Design and development of a novel 4-DOF parallel kinematic coordinate measuring machine (CMM). International Journal of Computer Integrated Manufacturing (32:8), 750-760. 